\title{
Surgical and Biomechanical Perspectives on Osteoarthritis and the ACL Deficient Knee: A Critical Review of the Literature
}

\author{
Richard Z. Fu ${ }^{*}, 1$ and David D. Lin ${ }^{2}$ \\ ${ }^{I}$ Department of Medicine, Imperial College London, UK \\ ${ }^{2}$ Department of Surgery, West Middlesex University Hospital, Imperial College Academic Health Sciences Partner, \\ London, $U K$
}

\begin{abstract}
This review was undertaken to better understand the debate regarding the issue of osteoarthritis associated with anterior cruciate ligament (ACL) injuries, from a surgical and biomechanical standpoint. Much of the current debate focuses on contributory surgical factors and their relative roles in increasing or decreasing the risk of future osteoarthritis development, primarily highlighting the controversy over whether reconstructive surgery itself is necessarily protective. This review addresses the evolution of ACL reconstruction techniques over time, and with a view to thoroughly examine the role of surgery, outcome differences in procedural technique are reviewed, with a focus on open versus arthroscopic methods, graft choice and the use of a double versus single bundle reconstruction technique.

Moreover, other potentially important contributory factors are identified and discussed, such as intrinsic biomechanical alterations sustained at the time of initial injury, and how these may have a more significant role with regard to future osteoarthritic changes in the knee than previously attributed.
\end{abstract}

Keywords: Anterior cruciate ligament, ACL, biomechanics, graft choice, injury, osteoarthritis, reconstruction, review.

\section{INTRODUCTION}

ACL reconstructive surgery has long been accepted to improve stability and improve function of the knee after acute ACL tears [1-7]. It has also been well documented that the natural progression of ACL injuries if left untreated may likely predispose to the early development of osteoarthritis [8-19]. It had therefore been assumed by some that restoring stability through reconstruction could also decrease the risk of future osteoarthritis [20-25]. This assumption is still widely preached by members of the sports medicine community [26]. However, the degree of protection it confers against osteoarthritis is debatable.

Some long term studies have found a significant counterintuitive increase in the development of osteoarthritis in patients post ACL reconstructions, when compared to matched controls of the general population [14,27,28]. The question of whether reconstructive surgery itself conveys a risk naturally arises. The debate over this issue has led to some controversy, with one author going so far as to suggest that the risk conferred by surgery was greater than that conferred by more conservative forms of treatment [29].

Nevertheless, most authors still believe that ACL reconstruction confers protection against osteoarthritis [26]. However, supporting theories though convincing, remain to be firmly proven. To date, only theoretical speculation abounds, as no randomised control studies have been done comparing surgery to conservative treatment of ACL tears

*Address correspondence to this author at the Department of Medicine, Imperial College London, South Kensington Campus, London SW7 2AZ, UK; Tel: +44 (0)20 7589 5111; E-mail: richard.fu12@imperial.ac.uk
[30]. Other authors suggest that it is the joint injury itself that confers the risk of future osteoarthritis [26,28,30,31], and hence it is pointless to debate over forms of management, when the damage has essentially already been done.

Through careful analysis, this review seeks to tease out the factors at the heart of this debate and determine as far as possible, their roles in the association between ACL injury and future osteoarthritis. In order to thoroughly examine the role of surgery, differences in procedural technique are examined, with focus on open versus arthroscopic methods, graft choice and the double bundle versus standard single bundle reconstruction technique.

\section{MATERIALS AND METHODS}

A combined Medline search using the following terms: 'osteoarthritis, 'knee', 'anterior cruciate ligament surgery' and 'biomechanics' was performed. Paper abstracts were reviewed and papers either identified through the initial search, or from subsequent reading, with content relevant to the aims and objectives of this review, were examined in greater detail.

\section{REVIEW FINDINGS}

\section{Comparing Surgery and Conservative Treatment}

The period spanning the late 70 s to early 80 s generated substantial literature associating ACL rupture with subsequent onset of osteoarthritis [13,14,27,32]. Many studies showed that the conservative treatment of ACL ruptures resulted in a significant increase in osteoarthritis [13,14,33-37]. This prevalent view at the time resulted in the assumption that followed during the late $80 \mathrm{~s}$ and early $90 \mathrm{~s}$ 
that ACL reconstruction would be the solution to prevent later osteoarthritis in ACL injured knees [21-25].

This view did not go unchallenged for too long, with a notable publication by Daniel et al. in 1994 suggesting that ACL reconstruction surgery actually conferred a greater risk in osteoarthritis development when compared to conservative treatment [38]. Though this review found no other authors as seemingly convicted over this former point as Daniel et al., it did find that many later studies within the past decade at least echo the view that ACL reconstruction has not been shown after long term follow up, to be protective against the development of osteoarthritis $[39,40]$.

Seon et al., for example, reported degenerative osteoarthritis in $43 \%$ of their 58 ACL reconstructed patients at follow up after an average of 11.2 years, and also found that the region most often affected was the medial compartment of the knee [41]. In their 14 year follow up study of former soccer players, von Porat et al. found a high prevalence of knee osteoarthritis on radiographic examination of 122 male soccer players. A rather startling $78 \%$ showed radiographic change, with $41 \%$ demonstrating changes equivalent to grade 2 changes on the Kellgren and Lawrence scale. Importantly, no difference in such outcome was determined between those who had undergone reconstruction and those who had not [39]. A 17 year retrospective follow up study by Selmi et al. of 103 patients with ACL reconstructed knees showed less startling, yet significant results. About half (49\%) of the patients exhibited radiographic change, with $22.7 \%$ showing pre-osteoarthritic change (IKDC grade C) and $4.7 \%$ showing established osteoarthritis (IKDC grade D). What was more significant about this study was the drastic difference in outcome when patients were classified based on whether they had undergone medial medial meniscectomy [42].

Of the patients who had a medial meniscectomy, $37.2 \%$ had pre or established osteoarthritis, versus just $13.5 \%$ in those who had not undergone this additional procedure [42]. In support of this finding was a recent large meta-analysis of 1554 ACL reconstructions by Claes et al., which showed that medial menisectomy dramatically increased the risk of osteoarthritis development, the analysis quoting an odds ratio of 3.54 for the development of osteoarthritis with associated menisectomy [31].

Similarly, an increased association with osteoarthritis in subjects with meniscus injury was found in other studies reviewed $[8,28,30,39,42,43]$. Von Porat et al. reported in their study that patients who had a meniscus tear were $28 \%$ more likely to exhibit changes, mirroring Kellgren and Lawrence grade 2 or worse, than patients without one at 14 year follow up [39]. Louboutin et al, in a recently published review of risk factors associated with the development of osteoarthritis post ACL reconstruction, highlighted meniscal injury and chondral damage as important factors [44].

It is worth highlighting that an important conclusion of Louboutin et al.'s review was that reconstruction was beneficial to decreasing the progression of osteoarthritis in ACL deficient knees, identifying anterior tibial displacement as a principle arthogenic factor that was corrected after ACL reconstruction [44]. However findings of the other studies highlighted were largely inconclusive as to whether ACL reconstruction conferred protection against osteoarthritis, but do suggest strongly that other factors play significant roles in its progression.

Despite the lack of clarity over whether ACL reconstruction confers protection against osteoarthritis, logical arguments both for and against it can nevertheless still be made.

An argument for reconstruction, being a strong one in theory at least, is that restoration of joint stability reduces the risk of further injury, specifically to the meniscus [8,28], whose clear association with later osteoarthritis has already been highlighted.

Conversely, speculative arguments against surgery abound. It has been suggested that operative trauma itself and the occasional need for re-operation confer risk [28]. Pre-tensioning of the graft has also been shown to alter joint kinematics and lead to later knee arthrosis $[45,46]$. It has also been speculated that the arthrofibrosis and decreased range of motion which may occur post operation, could lead to accelerated knee deterioration [28]. Other authors have also suggested that patello-femoral pain, which often occurs in patients who undergo ACL reconstruction with a patellar tendon graft (which bear in mind, was the pre-dominant graft of choice instudies comparing surgery to conservative treatment) may be linked to the long-term development of patellofemoral arthrosis [47].

Interestingly, with regards to patellofemoral osteoarthritis, Lohmander et al. in their 12 year follow up study of 103 female soccer players, found radiographic signs of patellofemoral osteoarthritis to be more common in subjects who had undergone reconstruction, reporting that "significantly more patients with an ACL-reconstructed knee had radiographic changes in the patellofemoral joint compared with non-surgically treated patients (25 of 41 (61\%) versus 7 of 25 (28\%); $\mathrm{P}=0.01)$ " [40]. Though these findings may seem to favour conservative treatment, the issue is not so clear cut.

Lohmander et al. admitted uncertainty over whether this finding was related to knee surgery in general or more specifically, influenced possibly by their surgical method (according to them, almost all procedures were performed with the open technique)[40]. Furthermore, overall, they found no significant differences in osteoarthritis classifications and symptoms between study subjects who had undergone surgery and those who had not [40]. The issue of whether surgical method confounded their findings is thus in question. Conversely, despite also finding a greater prevalence of osteoarthritic change in subjects who received reconstruction and returned to sport than those who did not have reconstruction but nevertheless returned to sport, Fink et al. in their own study, reported at the same time, a lesser severity in the former group [48].

It is difficult to fairly assess findings and draw conclusions from across the various studies that have been published, despite many reporting findings of statistical significance. This is due to a lack of concordance across published studies to date with respect to the type of surgical procedure performed and the methods used to evaluate the development of osteoarthritis [39]. Different studies also studied different subsets of patients, athletes naturally 
putting more demand on their knees than the general populous. We also have no way of accounting for the difference in levels of physiotherapy received by each patient or even their compliance with restrictions in activity in the post-operative setting. These confounding factors make answering the question on whether reconstruction protects against osteoarthritis very difficult.

Furthermore, ACL reconstructive surgery itself has evolved through the past decade and it is difficult to evaluate study findings at face value or make fair comparisons, without considering the time era within which a particular study's reconstructions were performed. This would closely relate to the procedural technique and method considered to be best practice at that time. As we know, best practice can change with time, and this can be well reflected by observing the evolution of ACL reconstruction over the past two decades. The procedure has evolved greatly; from its humble beginnings of attempting to repair torn ACLs via suture as opposed to complete reconstruction with a graft [49]. The choice of graft itself has changed from synthetic allografts to autografts, as has the approach to surgery, with arthroscopic surgery being favoured over the open approach. This constant evolution has since factored in a developing appreciation for biomechanical variances [50], and recent focus has shifted to the new double bundle technique.

This important need to consider changes in operative method is highlighted by findings reported by Kullmer et al. in 1994, in their follow up of 77 patients after reconstruction using the Trevira Hochfest synthetic ligament, where they reported a statistically significant increase in osteoarthritis in their patients at follow up [8]. It is possible, in this case, that the synthetic nature of the graft used could itself have contributed significantly to the observed increase, thus confounding their results, since the use of synthetic ligaments, as we now know several years later, has been shown to be associated with future onset of osteoarthritis. It has been suggested in other research that particles of such ligaments may cause extensive synovitis and resultant long term joint effusion, which may subsequently increase the risk of cartilage damage and thence that of osteoarthritic progression [51, 52].

It is therefore our opinion that different operative procedures and techniques, which evolve with time, can significantly confound reported differences in study findings. It is in this same vein that further analysis in the hope to better understand possible confounding factors, is undertaken, and highlighted in the following sections.

\section{COMPARING OPEN AND ARTHROSCOPIC RECON- STRUCTIVE SURGERY}

Studies specifically comparing open and arthroscopic techniques in specific relation to osteoarthritis were not found during the course of this review and hence it is admittedly difficult to accord each a fair assessment. Nevertheless, reasonable deductions could be made upon review of various author's opinions in the literature studied.

As previously mentioned, it is important to take study findings within context. Despite Lohmander et al.' s rather convincing finding which associated patellofemoral osteoarthritis more with surgically repaired knees than with conservatively treated ones [40], it is important to remember that almost all the subjects within that study were treated with open reconstructions. It is possible, as they also hint toward, that the open, more invasive technique could have itself given rise to this finding of reported significance.

Attempts to critically compare reported findings of osteoarthritis across studies, with respect to whether an open or arthroscopic technique was used, proved inconclusive. Most reported an incidence ranging from $40 \%$ to $50 \%$ at follow up [41, 42, 53], with no obvious statistical difference with respect to whether surgery was done arthroscopically or with an open technique. There was also a lack of congruence between studies with respect to evaluation and classification methods, time between injury and reconstruction, and follow up periods [41, 42, 53-55].

Nevertheless, the open technique has been pegged as a possible factor in the development of osteoarthritis associated with ACL reconstruction [56]. Having highlighted this possibility in their paper, Lohmander et al. wrote that newer arthroscopic procedures, at least in the short term post-operative time span, may be associated with less morbidity [43]. It is a fair deduction to make; that less morbidity during the short term post-operative period is favourable, in relation to limiting knee trauma and hence the future development of osteoarthritis.

Authors have also suggested that findings of altered bone metabolism, reflected by an increase in bone scintigraphic uptake by ACL reconstructed knees years after surgery [57], may have been caused by the open surgical approach [5557]. Jarvela et al., who reported a $47 \%$ incidence of osteoarthritis in their study of 100 ACL reconstructed knees at mean 7 years follow up, also suggested that the large notchplasty performed during their miniarthrotomy technique may have played a part in the development of patellofemoral osteoarthritis in their studied knees [53].

Despite the lack of well-founded statistical comparisons, it is reasonable to deduce that the trend in the literature reviewed points in favour of arthroscopic techniques.

\section{COMPARING PATELLAR TENDON AND HAMST- RING TENDON GRAFT CHOICE}

It has been widely regarded that both grafts lead to a good overall clinical outcome, with most modern studies publishing high rates of patients in both groups attaining a functionally stable knee that they are most often satisfied with [1-5]. However, virtually all of these comparative studies did not include long term follow up assessments of osteoarthritis, until recently.

Initial 5 and 7 year comparison studies from the Australian Institute of Musculoskeletal Research reported that patients in the patellar tendon group had a significantly greater risk of developing early osteoarthritic changes $[1,4]$. The difference between graft groups was insignificant at 2 years, but was significant by year 5 of follow up and onwards. The incidence of osteoarthritic change had increased by $17 \%$, from $1 \%$ to $18 \%$, in the patellar tendon group within the 3 years between follow up [1]. By the $7^{\text {th }}$ year of follow up, this incidence rose to $45 \%$ in the patellar tendon group. In comparison, the incidence of such change in the hamstring tendon group was much lower at $14 \%$ after 7 years [4]. This trend was subsequently 
reinforced with further results published recently at 15 years follow up $[58,59]$. Of those who had undergone reconstruction with the patellar tendon graft, half $(51 \%)$ had radiographic evidence of osteoarthritis [58]. This was in striking contrast to the patients in their hamstring group, of which just 7\% showed radiographic evidence [59].

Sajovic et al. conducted a prospective RCT comparing osteoarthritis rates between patellar and hamstring tendon grafts. At 5 years, the study found that Grade B abnormal radiographic findings were seen in 50\% (13/26) of patients in the patellar tendon group and in 17\% (5/28) of patients in the hamstring tendon group $(p=0.012)$ [60]. This finding was mirrored by Pinczewski et al. in a cohort study which followed up 180 patients for 10 years. They too reported a statistical significant increase in radiologically evident osteoarthritis in patellar grafts as compared to hamstring grafts [61].

There are several theories that could explain these findings. As highlighted previously, the patellofemoral pain that commonly affects patients with a patellar tendon graft has been suggested to be responsible for patellofemoral joint osteoarthritis in the long term [28] Alternatively, Roos et. al suggested that reduced quadricep strength observed in patellar graft patients at follow up could increase the risk of future patellofemoral osteoarthritis [30]. However, their deduction was based on the findings of just one recent randomised control trial (RCT) (the RCT was also not well referenced in their paper, and hence this review was unable to analyse its claims). A large number of graft comparison studies showed on the other hand, that such strength deficits were either not apparent or at least no longer significant at final follow up [2,7].

What seems to explain the finding of difference more specifically, and what may just be the 'holy grail' in understanding the wider issue explored in this review, is altered biomechanics at the joint dependent on the type of graft used for reconstruction. Although Feller et al. reported finding abnormal biomechanical moments about the knee in both patellar and hamstring tendon groups, they deferred in their respective natures. A reduced external extension moment at terminal stance was found in the hamstring tendon group, while a reduced external knee flexion moment at mid stance was found in the patellar tendon group [62]. Feller et al. wrote that this altered moment found in the patellar tendon group mimicked that which was observed in single limb landing tasks [63], and therefore concluded that such moments, possibly akin to lessened attenuation of forces passing through the knee joint, could be responsible for the increased incidence of osteoarthritis reported in the patellar tendon group [62].

When Allen $e t$ al. measured in situ forces at the knee in knees reconstructed with either graft, they arrived at similar findings and conclusions [64]. They reported that reconstruction with either graft failed to approximate forces similar to those found in ACL intact knees. More importantly, they also found under $110 \mathrm{~N}$ of anterior tibial loading, (as shown in Fig. 1) that 'the BPTB (patellar tendon) graft carried significantly smaller in-situ forces at 60 and 90 degrees when compared to the intact ACL, whereas the QST/G (hamstring tendon) graft carried significantly larger in-situ forces at 60 and 90 degrees than the BPTB (patellar tendon) reconstruction' [64]. They therefore concluded that using a hamstring graft more closely mimicked in-situ forces secondary to anterior tibial loading in the intact ACL at a wider range of knee flexion angles and therefore carried considerable advantage over using a patellar tendon graft [64]. Having already ascertained that all reconstructions in studies reporting an increased incidence of osteoarthritis in reconstructed knees used a patellar tendon graft, one cannot help but wonder whether an incidence as large would have been reported if hamstring grafts had been used instead.

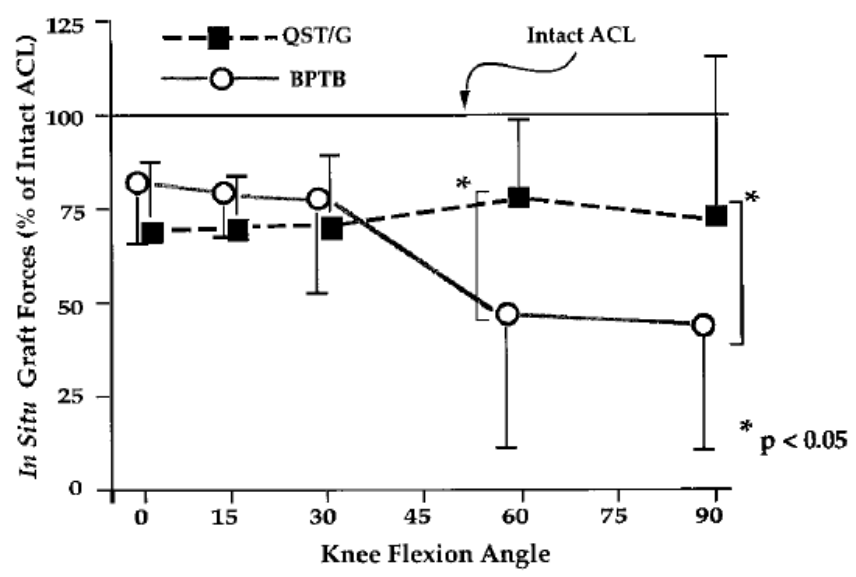

FIG. 8. In-situ forces in the reconstructed grafts (expressed in percent of the in-situ forces in the intact ACL) as a function of flexion angle, under $110 \mathrm{~N}$ anterior tibial loading.

Fig. (1). Reprinted from Osteoarthritis and Cartilage, Vol. 7 Issue 1, Allen CR, Livesay GA, Wong EK, Woo SLY, Injury and reconstruction of the anterior cruciate ligament and knee osteoarthritis, pages no. 110-121, 1999, with permission from Elsevier.

It would be interesting if we could determine the factors which cause such altered biomechanics. Some authors speculate that the patella infera (patellar tendon shortening) which has been documented to occur after reconstructions using the patellar tendon $[65,66]$, could alter biomechanics at the knee joint. Patellar adhesion to the anterior tibia, which gives rise to an apparent patella infera [67], could alter mechanics in various ways. Such adhesion would direct the patellar tendon force more posteriorly, thus leading to increased patellofemoral joint reaction force. It could also decrease patellar mobility and alter the extensor mechanism moment, all of which alter biomechanics at the knee joint and ultimately, lead to the development of patellofemoral osteoarthritis [65]. Another factor, which may lead to a dysfunctional extensor mechanism in reconstructed knees using a patellar tendon autograft, is the surgical closure with sutures of the patellar tendon defect after having harvested the graft. Such closure could be partially responsible for the scarring and shortening of the patellar tendon [66].

Therefore, this exploration into graft comparison has not only resulted in the finding that hamstring tendon grafts may well prove advantageous in terms of limiting osteoarthritic progression in the long term, but has also revealed the significance of altered knee biomechanics after an ACL injury. 


\section{Comparing Double Bundle and Single Bundle Reconstruction}

Double bundle ACL reconstruction was introduced based on previous work with biomechanical cadaveric studies. The aim was to achieve better stability of the knee particularly in rotation by reconstructing the Posterior Lateral (PL) bundle in addition to the Anterior Medial (AM) bundle, which is normally reconstructed in isolation on single bundle repairs. Abnormal knee rotation was found to persist in single bundle reconstructions [68-70] resulting in abnormal knee kinematics. This has been implied in the development of osteoarthritis in reconstructed knees [71]. It is hoped that double bundle reconstruction would address this problem.

Double bundle reconstruction demonstrated this superior control of rotation in a number of studies. Seon et al. used a navigation system intra-operatively and reported a significant improvement in the rotational stability in double bundle compared with single bundle reconstruction ( 9.8 degrees in the double- and 5.6 degrees in the single-bundle groups, $\mathrm{p}<0.001)$ [72]. Kondo et al. similarly described notably better results whenevaluating patients based on the positivity of a pivot-shift test at 2 years follow-up; double bundle (+ result, 16\%; ++, 3\%) being significantly better than the single bundle reconstructions (+ result, 37\%; ++, $12 \%$ ) in 328 patients [73].

Considering trials that examined the restoration of rotational kinematics during functional activity, Hemmerich et al. captured 3 dimensional kinematic data during a dynamic cutting task and demonstrated that the double bundle reconstructed knees exhibited significantly less external rotational shift compared to the single bundle group [74]. Lam et al. used a high demand jump-landing and pivot task, capturing data using an optical motion analysis system [75]. This study found that there was no significant difference in tibial rotation between intact $\left(8.2^{\circ} \pm 2.6^{\circ}\right)$ and double bundle $\left(8.9^{\circ} \pm 3.0^{\circ}\right)$ reconstructed knees, essentially reporting a restoration of rotational knee stability after reconstruction [75].

In a recently published literature review of 14 RCTs and 2 Meta-analysis, Suomalainen et al. concluded that after double bundle reconstruction, rotational stability of the knee was better in $7(50 \%)$ studies, and anterior-posterior stability in $6(43 \%)$ [76]. The review also noted that knee scores were better in $5(36 \%)$ and that 3 trials $(21 \%)$ revealed less reoperation rates compared with single bundle reconstruction [76].

On the background of these promising results, trials comparing osteoarthritis differences of double bundle reconstruction were eagerly awaited. Unfortunately, studies so far have yet to show a difference in osteoarthritis rates post double bundle reconstruction. Ventura et al. retrospectively analysed 50 patients, 36 who underwent single bundle and 14 double bundle reconstructions, at a mean of 4.4 years post-surgery [77]. While the study reports clearly superior clinical assessment and instrument laxity testing in the double bundle group, it failed to show any significant difference in the rates of radiological assessed osteoarthritis when compared to single bundle reconstruction [77].
Suomalainen et al. published results of a prospective 5 year study of 90 patients in 2012 and found that while there were significantly fewer graft failures in the double bundle group, there were again no significant differences in radiological osteoarthritis when compared to the single bundlegroup [78].

It is worth noting that in view of the size of both the above mentioned groups studied, some caution should be made when interpreting these early results. It is also our opinion that longer term follow-up isnecessary before a definitive comparison can be made with regard to osteoarthritis rates in double versus single bundle reconstruction.

\section{FURTHER DISCUSSION}

An interesting study by Almekinders et al. may help illuminate not only the issue of altered biomechanics after an ACL injury, but also why recent studies have continued to associate ACL reconstructed knees with the subsequent onset of osteoarthritis. In this study, Almekinders et al., measured tibial position relative to the femur radiographically in three different patient groups. Group 1 consisted of patients who had had an ACL rupture but were not surgically treated, group 2 consisted of patients who had had reconstruction after an ACL rupture and group 3 was a control group with normal knees [79].

In the study, ACL reconstruction failed to restore the natural tibiofemoral relationship at the knee and was instead significantly associated with an anterior irreducible subluxation of the tibia. More interesting, was a similar finding of such subluxation in only members of group 1 who demonstrated osteoarthritic changes at the knee. Conversely, members of this group (i.e. patients who had had an ACL rupture but were not surgically treated) without radiographic evidence of osteoarthritis did not demonstrate such subluxation of the tibia [79].

This led the authors to suggest a possible association between irreducible tibial subluxation and osteoarthritis, and they theorised that such subluxation "could be the common pathway to osteoarthritis in both treated and untreated knees.' [79]. Though the authors admitted that they could not prove this concept, and a more recent study by Seon et al. found no significant correlation between the proposed association [41], if true, this theory could help explain why recent literature has reported increases in incidence of osteoarthritis after ACL injuries regardless of whether knees were subsequently treated with reconstructions or not. Just like most areas of contention in the wider issue, further research, such as longitudinal studies exploring the causal relationship are necessary before more concrete conclusions can be made.

Through their findings, Almekinders et al. also contributed a significant explanation of Daniel et al's unique findings reported a good decade earlier. Almekinders et al. suggested that the possible causal association between irreducible tibial subluxation and osteoarthritic change could help explain why Daniel et al. reported increased degenerative changes despite improved total anteroposterior tibial motion in ACL reconstructed knees [79]. 
With regard to the issue of biomechanics, Almekinders et al. also suggested that such irreducible tibial subluxation would likely alter normal knee kinematics, and that the altered rolling motion of the tibiofemoral joint could lead to increased osteoarthritic change [79]. Regardless of whether such subluxation could be the main cause of altered kinematics at the knee joint, it seems likely that the issue of altered biomechanics lies right at the heart of the modern debate regarding ACL injury and osteoarthritis.

Recent research from Stanford University showed that the ACL deficient knee is associated with altered load bearing within regions of the knee during normal function. The resultant, altered gait kinematics then cause accelerated cartilage thinning particularly within the medial compartment of the knee [80]. This not only highlights the inevitable degenerative change that awaits un-operated ACL injured knees, but also biomechanically explains Seon et al.'s reported finding that the medial compartment was more commonly affected in their ACL reconstructed patients with degenerative osteoarthritis [41].

Further work on the ACL deficient knee is nicely summarised by Chaudri et al., who described the loss of inherent knee stability and the alteration in the levels of compression and tension imposed on different parts of the cartilage post ACL rupture. The review proposed an interesting mechanism whereby this alteration of load on mature cartilage, which has a low adaptation potential and high metabolic sensitivity, resulted in premature osteoarthritis [81].

Studies so far reviewed seem to suggest that ACL deficiency predisposes the knee to osteoarthritis from a biomechanical point of view. To gain a better understanding of whether ACL reconstruction protects against this change or whether the intrinsic alterations in knee kinematics post reconstruction further predispose a patient to developing osteoarthritis, we have considered the following studies.

Various studies have investigated the alteration in gait post reconstruction. Gao et al. described a three dimensional joint kinematic study during dynamic exercise by getting patients who had normal, ACL deficient and ACL reconstructed knees to walk up and down stairs [82]. This study reported a residual varus deviation of the tibia and statistically reduced range of extension post reconstruction surgery [82]. This result was mirrored by Hall et al. in their comparison of lower extremity gait patterns in patients with ACL reconstruction to a control group [83]. Hall et al. also reported that the reconstruction group compensated for lower knee extension moments by increasing hip extension moments during stair ascent, and they postulated that loading on the joint/ articular cartilage was hence altered post reconstruction surgery [83].

Tashman et al. investigated the behaviour of the ACL reconstructed knee during dynamic functional loading by measuring knee kinematics as subjects ran downhill post reconstruction [84]. The study reports statistically significant external rotation of the tibia in the stance phase of running [84]. Interestingly, Stergiou et al. suggested that this excessive tibial rotation, which was not seen in healthy knees, caused loading of areas of cartilage that were not loaded normally and this subsequently predisposed the knee to osteoarthritic changes [85]. They hypothesised that the newer surgical techniques like the double bundle reconstruction could restore tibial rotation to normal levels and possibly prevent future knee pathology [85].

Imhauser et al. went on to describe a cadaveric study on 11 knees, assessing how ACL deficiency and subsequent reconstruction altered the contact stresses at the tibiofemoral joint [86]. They reported that while reconstruction reduced high stresses in the posterior medial compartment of the ACL deficient knee, it created abnormal contact stresses in other parts of the knee. These abnormal stresses were related to multi-planar variation in knee kinematics.

It is perhaps only through further research into knee kinematics that surgeons will better understand changes in biomechanics that still prevail despite reconstruction and which provide the pathway for unavoidable osteoarthritic change regardless of forms of treatment.

Other important factors to consider include the role of muscle dysfunction after injury and damage to the joint that is inevitably caused at the time of injury. Muscle dysfunction post injury has been speculated as an important cause of osteoarthritis by some authors [26,30,87]. Roos suggested that muscular dysfunction leads to increased joint loads and subsequent osteoarthritis [30]. Tsai et al. subsequently reported increased tibiofemoral compressive forces in a group of females who had undergone ACL reconstruction, compared to matched controls, when performing a single-leg drop-land task. The study demonstrated increased muscle cocontraction with peak tibiofemoral compressive forces being significantly higher in the reconstruction group when compared to the control group $(97.3 \pm 8.0 \mathrm{vs} 88.8 \pm 9.8 \mathrm{~N} / \mathrm{kg})$ [88]

It is believed that the ACL plays an important proprioceptive role in regulating muscle function [89], and its rupture, therefore inevitably starts off this degenerative 'domino effect'. The shortfall of current ACL reconstructive surgery is its inability to restore proprioceptive feedback loops that were present prior to rupture [90]. This could be another reason why osteoarthritic degenerative change is observed in both surgically and conservatively treated ACL injured patients.

Yet another reason for this finding, and the finding of increased risk of osteoarthritis with concomitant meniscal injury, could be the fact that the progression of osteoarthritis is more greatly affected by the damage to cartilage that occurs at the time of injury [26,28,30]. Research by Lohmander et al. showing that the type II collagen network of the joint is degraded by soluble molecular fragments released into the synovial fluid soon after joint injury [91], suggests that this is an important factor to consider in itself. It is also through consideration of this factor that a strong argument for ACL reconstruction can be made from the view point that reconstruction at the very least decreases the risk of osteoarthritis by restoring stability, thereby reducing the risk of subsequent meniscal lesions or further joint injury from occurring [8].

The surgical challenge which lies ahead therefore entails the consideration of a paradigm of various important aspects. It will only be through further research, with experiments exploring the theoretical links between previously mentioned factors and the development of osteoarthritis and with the 
Table 1. A Comparison of Various Surgical Techniques

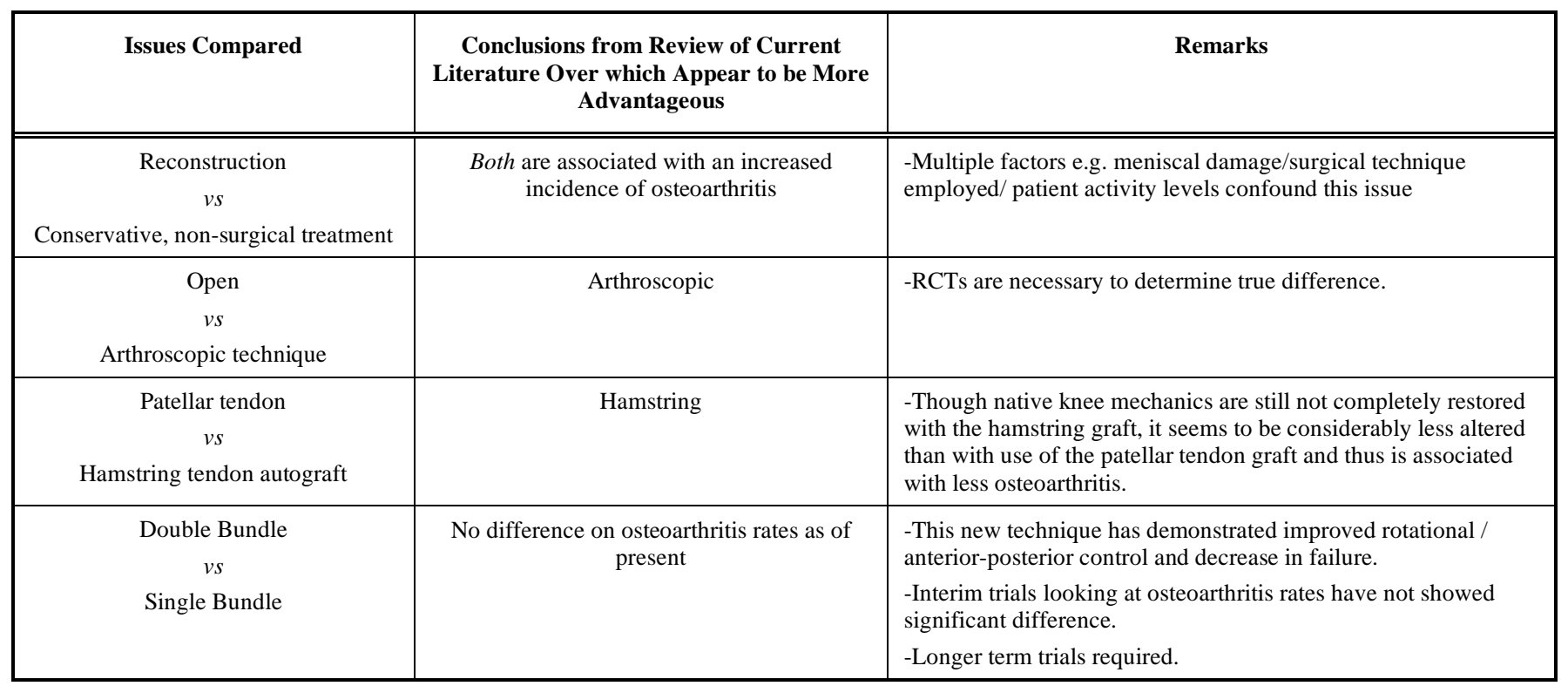

conduct of, ideally, further randomised controlled studies comparing various surgical options, that concrete progress can be made in the surgical management of the ACL deficient knee.

\section{CONCLUSION}

Certain justifiable conclusions based on currently available literature can be made and are summarised in Table 1.

As shown, it seems evident that both reconstruction and conservative treatment are associated with an increase in incidence of osteoarthritis. Nevertheless, this review also demonstrated the possible confounding effect of surgical method and technique through comparison of procedure (open $v s$ arthroscopic, double bundle $v s$ single bundle) and graft choice on this finding. It remains for well conducted RCTs to truly determine any difference between forms of treatment and for clinicians to ascertain their subsequent significance to current practice.

This review also identified and highlighted the importance of contributory factors to later osteoarthritis such as, concomitant meniscal injury, the issue of altered biomechanics and that of surgical method. The suggestion that hamstring grafts could be advantageous over patellar tendon grafts with regard to later osteoarthritis has foreseeable implications on the future evolution of ACL reconstructive surgery. The issue for example, of attaining maximum possible stability with a patellar tendon graft versus the increased risk of osteoarthritis will have to be properly considered by patients and surgeons alike.

The evolution of new surgical techniques like that of double bundle reconstruction, hold much promise for the future. The technique has already shown to be superior in rotational control of the knee and at least as good as single bundle reconstruction in anterior-posterior control. Despite the lack of early evidence for differences in osteoarthritis rates, we still have much to look forward to when longer term 10-15 year follow up rates are available.
We also note that the large majority of osteoarthritis diagnoses in reconstructed knees have so far been based on radiographic changes. What proportion of these patients are actually symptomatic and how many actually go on to require further knee replacements? This is surely an important consideration when advising patients on the management of their ruptured ACL.

Claes et al., in their meta-analysis of 16 studies (each with a minimum of 10 years follow up), published in 2012 , found that the actual rate of osteoarthritis was lower than commonly perceived at approximately $28 \%$ (453 out of 1554 reconstructions) [31]. It is our belief that through the continual evolution of surgical technique, informed by further research into understanding the pathogenesis of osteoarthritis, paired with robust comparisons of available treatment options, this rate can be lowered further still.

\section{CONFLICT OF INTEREST}

The authors confirm that this article content has no conflicts of interest.

\section{ACKNOWLEDGEMENTS}

The authors wish to thank the referees of this article for their helpful critique and input during the peer review process.

\section{REFERENCES}

[1] Pinczewski LA, Dee `han DJ, Salmon LJ, Russell VJ, Clingeleffer A. A five-year comparison of patellar tendon versus four-strand hamstring tendon autograft for arthroscopic reconstruction of the anterior cruciate ligament. Am J Sports Med 2002; 30(4): 523-6.

[2] Spindler KP, Kuhn JE, Freedman KB, Matthews CE, Dittus RS, Harrell FE. Anterior cruciate ligament reconstruction autograft choice: Bonetendon-bone versus hamstring does it really matter? a systematic review. Am J Sports Med 2004; 32(8): 1986-95.

[3] Freedman KB, D'Amato MJ, Nedeff DD, Kaz A, Bach BR Jr. Arthroscopic anterior cruciate ligament reconstruction: a metaanalysis comparing patellar tendon and hamstring tendon autografts. Am J Sports Med 2003; 31(1): 2-11.

[4] Roe J, Pinczewski LA, Russell VJ, et al. A 7-year follow-up of patellar tendon and hamstring tendon grafts for arthroscopic anterior cruciate 
ligament reconstruction:differences and similarities. Am J Sports Med 2005; 33(9): 1337-45.

[5] Yunes M, Richmond JC, Engels EA, Pinczewski LA. Patellar versus hamstring tendons in anterior cruciate ligament reconstruction: a metaanalysis. Arthroscopy 2001;17(3):248-57.

[6] Gulick DT, Yoder HN. Anterior cruciate ligament reconstruction: clinical outcomes of patella tendon and hamstring tendon grafts. J Sports Sci Med 2002; 1(3):63-71.

[7] Aune AK, Holm I, Risberg MA, Jensen HK, Steen H. Four-strand hamstring tendon autograft compared with patellar tendon-bone autograft for anterior cruciate ligament reconstruction a randomized study with two-year follow-up. Am J Sports Med 2001; 29(6): 722-8.

[8] Küllmer K, Letsch R, Turowski B. Which factors influence the progression of degenerative osteoarthritis after ACL surgery? Knee Surg Sports Traumatol Arthrosc 1994; 2(2): 80-4.

[9] Aubriot JH, Rivat P. Arthrose femoro-tibiale et laxité du genou avec atteinte du ligament croisé antérieur. Rev Chir Orthop 1983; (69): 2914.

[10] Dejour H, Walch G, Deschamps G, Chambat P. [Arthrosis of the knee in chronic anterior laxity]. Rev Chir Orthop Reparatrice Appar Mot 1987; 73(3): 157

[11] Dejour H, Dejour D, Ait Si Selmi T. Chronic anterior laxity of the knee treated with free patellar graft and extra-articular lateral plasty: 10-year follow-up of 148 cases. Rev Chir Orthop Reparatrice Appar Mot 1999; 85(8): 777-89.

[12] Fried J, Bergfeld J, Weiker G, Andrish J. Anterior cruciate reconstruction using the Jones-Ellison procedure. J Bone Joint Surg Am 985; 67(7): 1029-33.

[13] Jacobsen K. Osteoarthrosis following insufficiency of the cruciate ligaments in man: a clinical study. Acta Orthop 1977; 48(5): 520-6.

[14] McDaniel Jr W, Dameron Jr T. Untreated ruptures of the anterior cruciate ligament. A follow-up study. J Bone Joint Surg Am 1980; 62(5): 696

[15] Noyes F, Mooar P, Matthews D, Butler D. The symptomatic anterior cruciate-deficient knee. Part I: the long-term functional disability in athletically active individuals. J Bone Joint Surg Am 1983; 65(2): 154.

[16] Slocum DB, Larson RL. Rotatory instability of the knee: its pathogenesis and a clinical test to demonstrate its presence. Bone Joint Surg Am 1968; 50(2): 211-25.

[17] Maletius W, Messner K. Eighteen-to twenty-four-year follow-up after complete rupture of the anterior cruciate ligament. Am J Sports Med 1999; 27(6): 711-7.

[18] Neyret P, Donell ST, Dejour D, Dejour H. Partial meniscectomy and anterior cruciate ligament rupture in soccer players. A study with a minimum 20-year followup. Am J Sports Med 1993; 1(3): 455-60.

[19] Johnson RJ, Eriksson E, Haggmark T, Pope MH. Five- to ten-year follow-up evaluation after reconstruction of the anterior cruciate ligament. Clin Orthop Relat Res 1984; 183: 122-40.

[20] Jomha NM, Borton DC, Clingeleffer AJ, Pinczewski LA. Long-term osteoarthritic changes in anterior cruciate ligament reconstructed knees. Clin Orthop 1999 (358): 188

[21] Andersson C, Gillquist J. Treatment of acute isolated and combined ruptures of the anterior cruciate ligament A long-term follow-up study. Am J Sports Med 1992; 20(1):7-12.

[22] Dye SF, Chew MH. The use of scintigraphy to detect increased osseous metabolic activity about the knee. J Bone Joint Surg 1993; 75(9): 138806.

[23] Hazel WA Jr, Rand JA, Morrey BF. Results of meniscectomy in the knee with anterior cruciate ligament deficiency. Clin Orthop 1993; 292:32

[24] Kannus P, Jarvinen M. Conservatively treated tears of the anterior cruciate ligament. J Bone Joint Surg Am 1987; 69: 1007-12.

[25] Neyret P, Donell S, Dejour H. Results of partial meniscectomy related to the state of the anterior cruciate ligament. Review at 20 to 35 years. J Bone Joint Surg Br 1993; 75(1): 36-40.

[26] Shrier I. Recognizing and challenging dogma. Clin J Sport Med 2006; 16(2): 93-4.

[27] McDaniel Jr WJ, Dameron Jr TB. The untreated anterior cruciate ligament rupture. Clin Orthop 1983; 172: 158.

[28] Gillquist J, Messner K. Anterior cruciate ligament reconstruction and the long term incidence of gonarthrosis. Sports Med 1999; 27(3): 14356.

[29] Daniel DM. Who benefits from ACL surgery? Oral presentation on the American Academy of Orthopaedic Surgeons instructional course "Anterior cruciate ligament", Washington, 21-25 Feb 1992. 1992.
[30] Roos EM. Joint injury causes knee osteoarthritis in young adults. Curr Opin Rheumatol 2005; 17(2): 195-200.

[31] Claes S, Hermie L, Verdonk R, Bellemans J, Verdonk P. Is osteoarthritis an inevitable consequence of anterior cruciate ligament reconstruction? A meta-analysis. Knee Surg Sports Traumatol Arthrosc 2012; [Epub ahead of print]

[32] Noyes F, Matthews D, Mooar P, Grood E. The symptomatic anterior cruciate-deficient knee. Part II: the results of rehabilitation, activity modification, and counseling on functional disability. J Bone Joint Surg Am 1983; 65(2): 163.

[33] Egund N, Fridén T. Lesion of the anterior cruciate ligament and sagittal disalignment of the knee in weight-bearing. Acta Radiol 1988; 29(5): 559-63.

[34] Hackenbroich MHJ, Wirth CJ. Gonarthrose nach persistierender Kniestabilitat. . Z Orthop 1979; 117: 753-61.

[35] Lysholm J, Gillquist J. Evaluation of knee ligament surgery results with special emphasis on use of a scoring scale. Am J Sports Med 1982; 10(3): 150-4

[36] Menke W, Schneider T, Schmitz B, Michiels I. Nachuntersuchungsergebnisse bei unbehandelter vorderer Kreuzbandruptur. Sport-verl. Sportschad 1990; 4: 169- 74.

[37] Satku K, Kumar V, Ngoi S. Anterior cruciate ligament injuries. To counsel or to operate? J Bone Joint Surg Br 1986; 68(3): 458-61.

[38] Daniel DM, Stone ML, Dobson BE, Fithian DC, Rossman DJ, Kaufman KR. Fate of the ACL-injured patient a prospective outcome study. Am J Sports Med 1994; 22(5): 632-44.

[39] Von Porat A, Roos E, Roos H. High prevalence of osteoarthritis 14 years after an anterior cruciate ligament tear in male soccer players: a study of radiographic and patient relevant outcomes. Ann Rheum Dis 2004; 63(3): 269-73.

[40] Lohmander L, Östenberg A, Englund M, Roos H. High prevalence of knee osteoarthritis, pain, and functional limitations in female soccer players twelve years after anterior cruciate ligament injury. Arthritis Rheum 2004; 50(10): 3145-52.

[41] Seon JK, Song EK, Park SJ. Osteoarthritis after anterior cruciate ligament reconstruction using a patellar tendon autograft. Int Orthop 2006; 30(2): 94-8.

[42] Ait Si Selmi T, Fithian D, Neyret P. The evolution of osteoarthritis in 103 patients with ACL reconstruction at 17 years follow-up. Knee 2006; 13(5): 353-58.

[43] Lohmander L, Östenberg A, Englund M, Roos H. High prevalence of knee osteoarthritis, pain, and functional limitations in female soccer players twelve years after anterior cruciate ligament injury. Arthritis Rheum 2004; 50(10): 3145-52.

[44] Louboutin H, Debarge R, Richou J, et al. Osteoarthritis in patients with anterior cruciate ligament rupture: a review of risk factors. Knee 2009; 16(4): 239-44.

[45] Good L, Askew M, Boom A, Melby A. Kinematic in-vitro comparison between the normal knee and two techniques for reconstruction of the anterior cruciate ligament. Clin Biomech 1993; 8(5): 243-9.

[46] Van Heerwaarden R, Stellinga D, Frudiger A. Effect of pretension in reconstructions of the anterior cruciate ligament with a Dacron prosthesis. Knee Surg Sports Traumatol Arthrosc 1996; 3(4): 202-8.

[47] Sachs RA, Reznik A, Daniel DM, Stone ML. Complications of knee ligament surgery. In: Daniel DM, Akeson WA, O`Conrer JJ, Eds. Knee Ligaments.Structure, Function Injury Repair. NY: Reven Press 1990; pp. 505-20.

[48] Fink C, Hoser C, Benedetto KP. Development of arthrosis after rupture of the anterior cruciate ligament. A comparison of surgical and conservative therapy. Unfallchirurg 1994; 97(7): 357-61.

[49] Strand T, Mølster A, Hordvik M, Krukhaug Y. Long-term follow-up after primary repair of the anterior cruciate ligament: clinical and radiological evaluation 15-23 years postoperatively. Arch Orthop Trauma Surg 2005; 125(4): 217-21.

[50] Imhauser C, Mauro C, Choi D, et al. Abnormal tibiofemoral contact stress and its association with altered kinematics after center-center anterior cruciate ligament reconstruction An in vitro study. Am J Sports Med 2013; 41(4): 815-25

[51] Eberhardt C, Kurth A, Hailer N, Jäger A. Revision ACL reconstruction using autogenous patellar tendon graft. Knee Surg Sports Traumatol Arthrosc 2000; 8(5): 290-95.

[52] Dunn MG. Anterior cruciate ligament prostheses. In: Fahey TD, Ed. Encyclopedia of Sports Medicine and Science. Available from Internet Society for Sport Science: http://sportsci.org/encyc/aclprosaclpros.html [Accessed: 18th Nov`12] 
[53] Järvelä T, Paakkala $T$, Kannus $P$, Järvinen $M$. The incidence of patellofemoral osteoarthritis and associated findings 7 years after anterior cruciate ligament reconstruction with a bone-patellar tendonbone autograft. Am J Sports Med 2001; 29(1): 18-24.

[54] Hogervorst T, Rijcken THP, Rucker D, van der Hart, Cor P, Taconis WK. Changes in Bone Scans after Anterior Cruciate Ligament Reconstruction A Prospective Study. Am J Sports Med 2002; 30(6): 823-33.

[55] Jonsson H, Riklund-Åhlström K, Lind J. Positive pivot shift after ACL reconstruction predicts later osteoarthrosis 63 patients followed 5-9 years after surgery. Acta Orthop 2004; 75(5): 594-9.

[56] Cameron SE, Wilson W, St Pierre P. A prospective, randomized comparison of open vs arthroscopically assisted ACL reconstruction. Orthopedics 1995; 18(3): 249-52.

[57] Fritschy D, Daniel D, Rossman D, Rangger C. Bone imaging after acute knee hemarthrosis. Knee Surg Sports Traumatol Arthrosc 1993; 1(1): 20-7.

[58] Hui C, Salmon LJ, Kok A, Maeno S, Linklater J, Pinczewski LA. Fifteen-year outcome of endoscopic anterior cruciate ligament reconstruction with patellar tendon autograft for "isolated" anterior cruciate ligament tear. Am J Sports Med 2011; 39(1): 89-98.

[59] Bourke H, Gordon D, Salmon L, Waller A, Linklater J, Pinczewski L. The outcome at 15 years of endoscopic anterior cruciate ligament reconstruction using hamstring tendon autograft for 'isolated'anterior cruciate ligament rupture. J Bone Joint Surg Br 2012; 94(5): 630-7.

[60] Sajovic M, Vengust V, Komadina R, Skaza K. A prospective, randomized comparison of semitendinosus and gracilis tendon versus patellar tendon autografts for anterior cruciate ligament reconstruction Five-year follow-up. Am J Sports Med 2006; 34(12): 1933-40.

[61] Pinczewski LA, Lyman J, Salmon LJ, Russell VJ, Roe J, Linklater J. A 10-Year comparison of anterior cruciate ligament reconstructions with hamstring tendon and patellar tendon autograft. A controlled, prospective trial. Am J Sports Med 2007; 35(4): 564-74.

[62] Feller J. Anterior cruciate ligament rupture: is osteoarthritis inevitable? Br J Sports Med 2004; 38(4): 383-4.

[63] Webster K, Gonzalez-Adrio R, Feller J. Dynamic joint loading following hamstring and patellar tendon anterior cruciate ligament reconstruction. Knee Surg Sports Traumatol Arthrosc 2004; 12(1): 1521.

[64] Allen CR, Livesay GA, Wong EK, Woo SL. Injury and reconstruction of the anterior cruciate ligament and knee osteoarthritis. Osteoarthr Cartil 1999; 7(1): 110-21.

[65] Ahmad CS. The incidence of patellofemoral osteoarthritis and associated findings 7 Years after anterior cruciate ligament reconstruction with a bone-patellar tendon-bone autograft (Comment). . Am J Sports Med 2001; 29(5): 678-9.

[66] Järvelä T, Kannus P. The incidence of patellofemoral osteoarthritis and associated findings 7 Years after anterior cruciate ligament reconstruction with a bone-patellar tendon-bone autograft (Response Letter). Am J Sports Med 2001; 29(5): 678-9.

[67] Ahmad CS, Kwak SD, Ateshian GA, Warden WH, Steadman JR, Mow VC. Effects of patellar tendon adhesion to the anterior tibia on knee mechanics. Am J Sports Med 1998; 26(5): 715-24.

[68] Ristanis S, Giakas G, Papageorgiou C, Moraiti T, Stergiou N, Georgoulis A. The effects of anterior cruciate ligament reconstruction on tibial rotation during pivoting after descending stairs. Knee Surg Sports Traumatol Arthrosc 2003; 11(6): 360-5.

[69] Tashman S, Collon D, Anderson K, Kolowich P, Anderst W. Abnormal rotational knee motion during running after anterior cruciate ligament reconstruction. Am J Sports Med 2004; 32(4): 975-83.

[70] Brandsson S, Karlsson J, Swärd L, Kartus J, Eriksson BI, Kärrholm J. Kinematics and laxity of the knee joint after anterior cruciate ligament reconstruction pre-and postoperative radiostereometric studies. Am J Sports Med 2002; 30(3): 361-7.

[71] Andriacchi TP, Mündermann A, Smith RL, et al. A framework for the in vivo pathomechanics of osteoarthritis at the knee. Ann Biomed Eng 2004; 32(3): 447-57.
[72] Seon JK, Park SJ, Lee KB, Yoon TR, Seo HY, Song EK. Stability comparison of anterior cruciate ligament between double-and singlebundle reconstructions. Int Orthop 2009; 33(2): 425-9.

[73] Kondo E, Yasuda K, Azuma H, Tanabe Y, Yagi T. Prospective clinical comparisons of anatomic double-bundle versus single-bundle anterior cruciate ligament reconstruction procedures in 328 consecutive patients. Am J Sports Med 2008; 36(9): 1675-87.

[74] Hemmerich A, van der Merwe W, Batterham M, Vaughan C. Doublebundle ACL surgery demonstrates superior rotational kinematics to single-bundle technique during dynamic task. Clin Biomech 2011; 26(10): 998-1004.

[75] Lam M, Fong DT, Yung PS, Ho EP, Fung K, Chan K. Knee rotationa stability during pivoting movement is restored after anatomic doublebundle anterior cruciate ligament reconstruction. Am J Sports Med 2011; 39(5): 1032-8.

[76] Suomalainen P, Kannus P, Järvelä T. Double-bundle anterior cruciate ligament reconstruction: a review of literature. Int Orthop 2013; 37(2): 227-32.

[77] Ventura A, Legnani C, Terzaghi C, Borgo E. Single- and double-bundle anterior cruciate ligament reconstruction in patients aged over 50 years. Arthroscopy 2012; 28(11): 1702-9.

[78] Suomalainen P, Järvelä T, Paakkala A, Kannus P, Järvinen M. Doublebundle versus single-bundle anterior cruciate ligament reconstruction A prospective randomized study with 5-year results. Am J Sports Med 2012; 40(7): 1511-8.

[79] Almekinders LC, Pandarinath R, Rahusen FT. Knee stability following anterior cruciate ligament rupture and surgery. The contribution of irreducible tibial subluxation. J Bone Joint Surg 2004; 86(5): 983-7.

[80] Andriacchi TP, Briant PL, Bevill SL, Koo S. Rotational changes at the knee after ACL injury cause cartilage thinning. Clin Orthop 2006; 442: 39-44.

[81] Chaudhari A, Briant PL, Bevill SL, Koo S, Andriacchi TP. Knee kinematics, cartilage morphology, and osteoarthritis after ACL injury. Med Sci Sports Exerc 2008; 40(2): 215.

[82] Gao B, Cordova ML, Zheng N. Three-dimensional joint kinematics of ACL-deficient and ACL-reconstructed knees during stair ascent and descent. Hum Mov Sci 2012; 31(1): 222-35.

[83] Hall M, Stevermer CA, Gillette JC. Gait analysis post anterior cruciate ligament reconstruction: knee osteoarthritis perspective. Gait Posture 2012; 36(1): 56-60.

[84] Tashman S, Kolowich P, Collon D, Anderson K, Anderst W. Dynamic function of the ACL-reconstructed knee during running. Clin Orthop 2007; 454: 66-73

[85] Stergiou N, Ristanis S, Moraiti C, Georgoulis AD. Tibial rotation in anterior cruciate ligament (ACL)-deficient and ACL-reconstructed knees: a theoretical proposition for the development of osteoarthritis. Sports Med 2007; 37(7): 601-13.

[86] Imhauser C, Mauro C, Choi D, et al. Abnormal tibiofemoral contact stress and its association with altered kinematics after center-center anterior cruciate ligament reconstruction: an in vitro study. Am J Sports Med 2013 41(4): 815-25.

[87] Hurley MV. The role of muscle weakness in the pathogenesis of osteoarthritis. Rheum Dis Clin of North Am 1999; 25(2): 283-98.

[88] Tsai L, McLean S, Colletti PM, Powers CM. Greater muscle cocontraction results in increased tibiofemoral compressive forces in females who have undergone anterior cruciate ligament reconstruction. J Orthop Res 2012; 30(12): 2007-14

[89] Gandevia SC. Kinesthesia: roles for afferent signals and motor commands. In: Rowell LB, Shepherd JT, Eds Handbook of Physiology; Exercise: Regulation and Integration of Multiple Systems. New York: Oxford University Press, 1996.

[90] Bonfim TR, Jansen Paccola CA, Barela JA. Proprioceptive and behavior impairments in individuals with anterior cruciate ligament reconstructed knees. Arch Phys Med Rehabil 2003; 84(8): 1217-23.

[91] Lohmander LS, Atley LM, Pietka TA, Eyre DR. The release of crosslinked peptides from type II collagen into human synovial fluid is increased soon after joint injury and in osteoarthritis. Arthritis Rheum 2003; 48(11): 3130-9 